\title{
An Exploratory Study of Vocabulary Learning Strategies of Moroccan University Students
}

\author{
Salma Seffar ${ }^{l}$ \\ ${ }^{I}$ English Studies Department, Faculty of Education, Mohammed V University Souissi, Morocco
}

\begin{abstract}
The present study investigates the use of vocabulary learning strategies used by 124 Moroccan university students of English as a foreign language, 60 males and 64 females with a consideration of gender and proficiency. Strategy use is assessed through the SILL*(Oxford, 1990), and proficiency is determined by the subjects' study level. The findings are that the reported frequency of strategy use is moderate overall, with the students reporting most frequent use of compensation strategies and least of affective strategies. Female students show more frequent use of all six categories than male students, and fourth year university students employ compensation and memory strategies more often, whereas first year students employ metacognitive, cognitive, affective and social strategies more often. Cognitive strategies show the highest correlation with metacognitive and memory strategies. It is revealed that the students' gender and proficiency have a significant relationship with their use of learning strategies. Some implications of the findings are discussed along with suggestions for further research.
\end{abstract}

Keywords: Gender, learning strategies, second language vocabulary, vocabulary acquisition, proficiency.

\section{Introduction}

Vocabulary is central to language and of critical importance to the typical language learner. Two decades ago, the teaching and learning of vocabulary have been undervalued in the field of Second Language Acquisition (SLA) throughout its varying stages and up to the present day. SLA researchers and teachers have typically prioritized syntax and phonology as "more serious candidates for theorizing" (Richards, 1976, p. 77), more central to linguistic theory, and more critical to language pedagogy. Nevertheless, the development of modern applied linguistics, both theoretically and empirically, has pushed researchers to highlight the crucial role of vocabulary in L2 and FL learning.

The study of second language (L2) vocabulary acquisition has gained momentum in the last fifteen years, after a period of relative neglect. Long and Richards (1997:ix) note that since the mid-1980s there has been "a growing body of empirically based studies of such issues as the nature of the bilingual lexicon, vocabulary acquisition, lexical storage, lexical retrieval, and the use of vocabulary by second language learners". The emergence of such interest is quite logical taking into consideration the fact that lexical errors are the most common among L2 learners, as evidence from large error corpora suggests (Meara, 1984). Moreover, vocabulary errors seem to be not only the most disruptive ones for students (Politzer, 1978, as cited in Levenston, 1979), but also for native speakers in terms of interpretation. As Gass (1988) observes, grammatical errors still result in understandable structures, whereas vocabulary errors may interfere with communication. The centrality of the lexicon to both acquisition and use is expressed in the following quote by Hatch:

...it is the lexical level that adult second language learners claim is most important. When our first goal is communication, when we have little of the new language at our command, it is the lexicon that is crucial... the words... will make basic communication possible. (1983:74)

In the same vein, the importance of the study of L2 vocabulary is evident from several research findings cited by Gass and Selinker (2001: 372). According to Zimmermann (1997), Widdowson (1978) claimed: "native speakers can better understand ungrammatical utterances with accurate vocabulary than those with accurate grammar and inaccurate vocabulary." Levelt (1989:181, cited in Gass and Selinker 2001:373) even asserts that the L1 lexicon is the "driving force in sentence production" since it mediates conceptualization and the encoding of grammar and phonology.

Nevertheless, despite the impressive amount of recent research on vocabulary acquisition, the Moroccan context is unfortunately characterized by a scarcity of research on L2 vocabulary acquisition, in general, and vocabulary learning strategies, in particular. This study provides a review of recent research on vocabulary acquisition and pinpoints areas that need further exploration. To this end, this paper focuses on those areas, i.e., L2 vocabulary learning strategies and the relationship between gender and proficiency and the use of vocabulary strategies. An investigation of the vocabulary learning strategies employed by L2 learners when confronted by a new lexical item is of interest for two reasons. In the first place, the collected data will provide an example of the orchestration of L2 vocabulary learning strategies. Secondly, the data will act as an indicator for teachers of 
English, of some of the under-utilized strategies, on where to direct their efforts in teaching EFL university learners.

\subsection{Second Language Vocabulary Acquisition}

\section{Theoretical Framework}

Singleton (1999), citing Anglin's (1970) finding, gives the following main characteristics of L1 lexical development:

1. Syntagmatic / paradigmatic shift.

2. Progression towards a more abstract relationship between words.

3. Development of lexico-semantic classification of words (in terms hyponymy).

Of these shifts, only (1) is reflected in L2 vocabulary acquisition. That aside, L2 vocabulary acquisition differs considerably from its L1 counterpart in that it lacks a pre-speech dimension and takes place against the backdrop of an already existing mental lexicon (Singleton, 1999). This also means that, unlike L1 vocabulary acquisition, initial L2 learning does not usually involve the learning of new concepts. The assumption of conceptual equivalence of L1 and L2 lexical items is sometimes also referred to as Native Lexical Hypothesis. In terms of of development of lexical knowledge, learners move from mere word recognition to partial to complete lexical knowledge, although no native speaker ever attains complete knowledge of the full word meaning potential (Henriksen, 1999).

Henriksen (1999) also draws attention to the fact that the acquisition of word meaning actually involves two interrelated processes, item learning (adding to the lexical store by creating extensional links, i.e. form meaning mapping) and system changing (re-ordering/changing the lexical store via network building). The tendency in L2 vocabulary acquisition research has been to neglect the latter and focus on the former, which is much easier to test and assess than the slow process of network-building, which happens much later in language development.

\subsection{Processes of Vocabulary Acquisition - Implicit vs. Explicit Learning}

Applied linguistic theories of processes vocabulary acquisition range from implicit learning positions to those which hold that learners should be explicitly taught large amounts of vocabulary.Krashen (1989) exemplifies the implicit position. His Input Hypothesis assumes that we acquire language by understanding messages: "language is subconsciously acquired - while you are acquiring, you don't know you are acquiring; your conscious focus is on the message, not form" (Krashen, 1989, p.440). In other words, Implicit Vocabulary Learning Hypothesis holds that the meaning of a new word is acquired totally unconsciously as a result of abstraction from repeated exposures in a range of activated contexts. Explicit Vocabulary Learning Hypothesis, on the other hand, holds that the employment of a range of a range of vocabulary learning strategies can greatly facilitate and enhance vocabulary acquisition; on this view, learners are seen as active processors of information (Ellis, 1995). Both hypotheses also exist in a weak version, which only postulates some benefit of vocabulary learning strategies in the case of the Explicit Learning Hypothesis, and concedes that vocabulary acquisition may not be possible without atleast noticing the novelty status of a word in the case of Implicit Vocabulary Hypothesis.

\subsection{Vocabulary Learning Strategies}

The investigation of various methods of vocabulary presentation and their effect on retention is the main focus of research on vocabulary learning strategies. Schmitt and McCarthy (1997) realized that the great majority of learners seem to favor some form of mechanical strategy such as repetition over deeper, more complex ones, a finding that is disappointing in the light of the DOPH predictions. For instance, Gu and Johnson (1996) investigated the vocabulary learning strategies used by L2 Chinese learners of English and the relationship between vocabulary learning strategies use and learning outcomes as measured in terms of vocabulary size and general language proficiency. They found the 'shallow' strategy of visual repetition to be the strongest negative predictor of learning outcome, as opposed to deeper strategies such as contextual guessing, dictionary use, note taking and metacognitive strategies. In the same vein, in a study investigating the strategy use of Japanese university students, Mochizuki (1999) found that more proficient students use cognitive and metacognitive strategies more frequently than less proficient students. Concerning the question of causality of the strategy use/L2 proficiency relationship, Green and Oxford (1995) suggest a causal relationship but see it as an indirect 'spiral' rather than a straight ascending arrow. That is, active use of strategies lead to higher proficiency which in turn makes it more likely students will choose these strategies.

\subsection{Taxonomies of vocabulary learning strategies}

Vocabulary learning strategies is a relatively new area of study. In addition, although individual vocabulary 
learning strategies have been increasingly researched, only few researchers have attempted to develop a taxonomy of vocabulary learning strategies and investigated vocabulary learning strategies as a whole.

The first is Stoffer (1995). She developed a questionnaire which contained 53 items designed to measure specifically vocabulary learning strategies. She administered this Vocabulary Learning Strategy Inventory (VOLSI) and the SILL to 707 students at the university of Alabama. Both sets of materials were found to be very reliable (the internal consistency reliability coefficients were .90 and .93 ), although there remains an issue regarding the reliability since the reliability coefficient for each category was not shown. At any rate, Stoffer demonstrated that the 53 items on the VOLSI clustered into nine categories by factor analysis as follows:

Strategies involving authentic language use

Strategies used for self-motivation

Strategies used to organize words

Strategies used to create mental linkages

Memory strategies

Strategies involving creative activities

Strategies involving physical action

Strategies used to overcome anxiety

Auditory strategies

The other researcher who investigated many strategies altogether is Schmitt (1997), who proposed his own taxonomy of vocabulary learning strategies. His scheme is somewhat different from Stoffer's. He distinguished the strategies which learners use to determine the meaning of new words when they first encounter them from the ones they use to consolidate meanings when they encounter the words again. The former includes determination and social strategies, and the latter includes social, memory, cognitive, and metacognitive strategies. The social strategies are included in the two categories because they can be used for both purposes. This categorization is based, in part, on the Oxford's (1990) classification scheme.

Schmitt defined each category as follows. Determination strategies are used "when faced with discovering a new word's meaning without recourse to another person's expertise" (p. 205). Social strategies are used to understand a word "by asking someone who knows it" (p. 210). Memory strategies are "approaches which relate new materials to existing knowledge" (p. 205). The definition of cognitive strategies was adopted from Oxford (1990) as "manipulation or transformation of the target language by the learner" (p. 43). Finally, metacognitive strategies are defined as " a conscious overview $\mathrm{f}$ the learning process and making decisions about planning, monitoring, or evaluating the best way to study" (p. 205)..

In sum, many researchers adopt Oxford's (1990) classification scheme (SILL) to investigate the use of vocabulary learning strategies. The SILL appears to be the only language learning strategy instrument that has been checked for reliability and validated in multiple ways (Oxford \& Burry-Stock, 1995). Besides, the SILL is valid in the sense that the six categories of the SILL measure the same construct, strategies.

\subsection{Factors affecting the choice of vocabulary learning strategies}

The relationship of the use of vocabulary learning strategies to success in mastering a second or foreign language, as well as to sex and other variables, has been the focus of a growing body of research. Oxford (1989) synthesized existing research on factors influencing the choice of learning strategies among L2 students and showed sex and ethnicity as determinants of strategy use. But MacIntyre (1994) asserts that the influence of these two factors "may be more clearly understood through the attitudinal, motivational, and learning style differences generally associated with gender and ethnicity" (p. 187). In the following discussion, the major factors, which seem to have implications for the present study, will be presented.

\subsubsection{Gender}

According to several studies, the sex of the students makes a significant difference in learning a second or foreign language, according to several studies (Politzer 1983, Lee 1994, and Kim 1995). All studies, which examined sex as a variable in the use of language learning strategies reported that significant sex differences almost always occurred in a single direction, showing greater use of language learning strategies by females. Politzer (1983) reported that females used social learning strategies significantly more than males. Ehrman and Oxford (1988), using the SILL with both students and instructors at the U.S Foreign Service Institute came to the conclusion that compared with males, females reported significantly greater use of language learning strategies in four areas: general study strategies, functional practice strategies, strategies for searching for and communication meaning, and self-management strategies. In short, most of the prior research showed significant differences between males and females in the use of strategies, with women's overall dominance in frequency and range of the strategies. 


\subsubsection{Proficiency Level}

According to several studies, language course level also influences how students learn foreign or second languages. Politzer (1983) found that course level influenced the learning strategy choice of foreign language learners, with higher-level students using more 'positive', student-directed, communicative or functional strategies. Chamot et al. (1987) discovered that cognitive strategy use decreased and metacognitive (planning, organizing, and evaluating) strategy used increased as foreign language course level increased, but that socialaffective strategy use remained low across all course levels. Advancement in course level or years of study does not necessarily mean that students use better strategies in every instance. Cohen and Aphek (1980), in studying English speakers who were learning Hebrew, discovered that both good and bad learning strategies appeared across course levels. Nevertheless, most of the research does indeed show that, in general, the more advanced the language leaner, the better the strategies used.

\subsection{Subjects}

\section{Methodology}

The subjects are 124 Moroccan university students learning English as a foreign language (EFL) at the faculty of Letters in Rabat. The 124 subjects - 64 girls and 60 boys- belong to two different EFL proficiency levels: first-year university learners and fourth-year university learners. The age of the subjects varies from 18 to 22 for first-year students and from 21 to 27 for fourth-year students. For the exact numbers of students at each of the two university year levels, see Table 1.

Table 1. Distribution of Subjects by Gender and University Level

\begin{tabular}{llll}
\hline & Boys & Girls & \\
\hline University Year Level & $\mathrm{N}$ & $\mathrm{N}$ & Total \\
First Year Level & 40 & 34 & 74 \\
Fourth Year Level & 20 & 30 & 50 \\
Total & 60 & 64 & 124 \\
\hline
\end{tabular}

The main criterion on which the selection of subjects has been established is their level of EFL proficiency. As the questions and hypotheses of the research imply, the level of EFL proficiency is expected to affect the subjects' use of vocabulary learning strategies. All these subjects have been haphazardly selected because three years of difference in their exposure to English should certainly have improved the fourth year students' level of EFL proficiency to a greater extent than the first year students. Equally important is the size of the two groups. This has been given prominent importance in this research. Both groups of subjects are considerably representative of the target university population since they both represent more than $10 \%$ of Rabat's university EFL learners in the first and fourth years correspondingly.

\subsection{Instrumentation}

The instrument used in the data collection is the Strategy Inventory for Language Learning (SILL) (Oxford 1990). The SILL, a self-reporting questionnaire is for students of English as a second or foreign language by requiring students to answer 50-item questions on their vocabulary- strategy use on a five-point Likert scale ranging from "never or almost never true" to "always or almost always true". The questionnaire consists of two parts: (1) questions to gain demographic information about the participants (the subjects did not give their names; only their gender, age and level of study were required) and (2) questions relating to the strategies that the participants may have used. The main distinction in this taxonomy is that between direct strategies (working with the language itself) and indirect strategies (general management of learning). Direct strategies are divided into three subclasses: memory strategies (strategies to store and retrieve aspects of the target language), cognitive strategies (strategies for using the language and for understanding how it works), and compensation strategies (strategies for overcoming deficiencies of knowledge in language). Indirect strategies include metacognitive strategies (strategies for planning, organizing and evaluating the learning process), affective strategies (strategies for regulating emotions to approach the task positively), and social strategies (strategies for working with others to get input and practice). For a detailed overview of Oxford's 19 groups which are further subdivided into 62 subsets.

In this study Oxford's classification scheme (SILL) is adopted because it is a reliable and valid questionnaire and appears to be the only language learning strategy questionnaire that has been extensively checked for reliability in multiple ways (Oxford, 1990). It is certainly true that the SILL is designed to investigate language learning strategies in general. However, it can be used to investigate vocabulary learning strategies, in particular, because the vast majority of language learning strategies listed in Oxford's taxonomy are either vocabulary learning strategies (all strategies in the memory category), or can be used for vocabulary learning tasks. 


\subsection{Learning Strategies Frequencies}

\section{Results}

To answer research question 1 (what type of strategies are used by first and fourth year university students to acquire new vocabulary in L2?) and 2 (what is the frequency of each strategy use? i.e. what learning strategies are used more often than others?), descriptive statistics of the questionnaire are shown in table 2. The mean scores of the six categories of vocabulary learning strategies used by Moroccan EFL university students are reported in Table 2, where it can be seen that all means fall between 2.4 and 3.1 on a scale of 1 to 5 , a range which Oxford (1990) defines as medium use. Thus, the subjects in this study used strategies at a medium level rather than a high level.

Table 2. Mean Scores and Standard Deviations of the SILL

\begin{tabular}{llll}
\hline Descriptions & Mean & SD & Rank \\
\hline Memory strategies & 2.74 & .58 & 4 \\
Cognitive strategies & 2.90 & .65 & 3 \\
Compensation strategies & 3.14 & .49 & 1 \\
Metacognitive strategies & 2.74 & .57 & 4 \\
Affective strategies & 2.43 & .46 & 5 \\
Social strategies & 2.94 & .64 & 2 \\
\hline
\end{tabular}

Table 2 presents rank ordering of the strategies according to their frequency of use. As seen in Table 2, all six categories of strategies are used by Moroccan EFL university students. More importantly, compensation strategies (6 items) which include such strategies as guessing and using gestures (e.g., switching to the mother tongue, using other clues, getting help and using a synonym), are used most frequently ( $\mathrm{M}=3.14)$, followed by social strategies $(M=2.94)$. Social strategies $(6$ items) are used for facilitating interaction by asking questions, and cooperating with others in the learning process, (e.g., asking for clarification, cooperating with others and developing cultural understanding). Cognitive strategies $(M=2.90)$ include 14 items and they are used for linking new information with existing schemata and for analyzing and classifying it. Cognitive strategies are responsible for deep processing, forming and revising internal mental models and receiving and producing messages in the target language (e.g., repeating, getting the idea quickly, analyzing and taking notes).

Memory and metacognitive strategies $(\mathrm{M}=2.74)$ have the same frequency. Memory strategies $(9$ items) are used for entering new information into memory storage and for retrieving it when need for communication. (e.g., grouping, representing sounds in memory, structured reviewing, using physical response). Metacognitive strategies (9 items), on the other hand, are techniques used for organizing, planning, focusing and evaluating one's own learning. (e.g., linking new information with already known one, seeking practice opportunities, and self- monitoring).

Finally, affective strategies (6 items) ranked the lowest $(M=2.43)$. Affective strategies are used for handling feelings, attitudes and motivations. (e.g., lowering anxiety by use of music, encouraging oneself and discussing feeling with others). The preference of compensation strategies may be explained by the need to cope with various communicational, interactional situations in the students' English class and suggests that they employ compensation strategies to make up for missing knowledge.

\subsection{Relationship between strategies}

Correlation of strategies with each other is conducted to provide more information about the target population in terms of its answers' consistency and to identify a pattern, if there is one.

Table 3. Correlation Analysis among the SILL Categories

\begin{tabular}{llll}
\hline Category & Memory & Cognitive & Compensation \\
\hline Memory & 1 & & \\
Cognitive & $0.76^{* *}$ & 1 & \\
Compensation & $0.51^{* *}$ & $0.57^{* *}$ & 1 \\
Metacognitive & $0.76^{* *}$ & $0.82^{* *}$ & $0.51^{* *}$ \\
Affective & 0.45 & $0.46^{* *}$ & $0.34^{* *}$ \\
Social & $0.76^{* *}$ & $0.74^{* *}$ & $0.61^{* *}$ \\
\hline
\end{tabular}

$(* * \mathrm{p}<.01$, denotes significance at $1 \%)$

The relationship between the six categories of language learning strategies is shown in Table 3. The six categories are related to each other in a moderate to a strong fashion. Table 3 .shows that the strongest significant relationship is between metacognitive and cognitive strategies $(\mathrm{r}=.82)$. Next, memory strategies are more strongly related to cognitive strategies $(\mathrm{r}=.76)$ and metacognitive strategies $(\mathrm{r}=.76)$ than compensation $(\mathrm{r}=.51)$ and affective strategies $(r=.45)$. This result could indicate that the more memory the students use, the more cognitive and metacognitive strategies they use and the less affective strategies they reportedly use. The weakest relationship was between affective and compensation strategies $(r=.34)$. Table 3 also shows that cognitive strategies have the strongest correlation with other strategies i.e. metacognitive $(0.82)$, memory $(0.76)$, social 
(0.74), and compensation strategies (0.57). This means that the students who use cognitive strategies are often inclined to use other strategies, too.

\subsection{Relationship between strategy use and proficiency level}

In order to answer research question 3 (is there a significant difference in strategy use due to language proficiency as reflected by one variable: study level?), mean scores of SILL categories by proficiency level were run.

Table 4. Mean Scores of SILL Categories by Proficiency Level

\begin{tabular}{cccccc}
\hline & First Year $(\mathbf{n}=\mathbf{7 4})$ & \multicolumn{4}{c}{ Fourth Year $(\mathbf{n = 5 0})$} \\
\hline Description & Mean & SD & Mean & SD & p \\
Memory & 2.73 & .63 & 2.75 & .53 & 0.054 \\
Cognitive & 2.92 & .69 & 2.87 & .62 & 0.060 \\
Compensation & 3.07 & .46 & 3.21 & .52 & 0.052 \\
Metacognitive & 2.78 & .62 & 2.71 & .52 & 0.064 \\
Affective & 2.44 & .52 & 2.42 & .39 & 0.061 \\
Social & 2.97 & .68 & 2.93 & .60 & 0.069 \\
\hline
\end{tabular}

Table 4 shows the differences between the mean scores of first and fourth year students. There is no evidence that students who belong to a certain university year show higher strategy use in all six categories. Fourth year students have higher mean scores than first year students in two of the strategy groups, compensation (3.21 and $3.07)$, and memory (2.75 and 2.73) respectively. In contrast, the mean score of first year students is higher in the other four strategy groups, metacognitive $(2.78,2.71)$, cognitive $(2.92,2.87)$, affective $(2.44,2.42)$ and social $(2.97,2.93)$ strategies respectively. However, the difference is not statistically significant.

More precisely, fourth year students use compensation and memory strategies more often than their first year counterparts. First year students, on the other hand, use the other four strategies, metacognitive, cognitive, affective and social strategies more often than fourth year students. The individual SILL items of compensation strategies that the fourth year students report using more frequently are "to understand unfamiliar English words, I make guesses", "I make up new words if I do not know the right ones in English" and "if I can't think of an English word, I use a word or phrase that means the same thing". As for social strategies, table 4 shows that first year students use social strategies more often than fourth year students.

\subsection{Relationship between strategy use and gender}

To determine the effect of gender variable on strategy use and, hence, answer research question 4, mean scores of SILL categories by gender were carried out.

Table 5. Mean Scores of SILL categories by Gender

\begin{tabular}{|c|c|c|c|c|c|}
\hline & \multicolumn{2}{|c|}{ Boys $(n=60)$} & \multicolumn{2}{|c|}{ Girls $(n=64)$} & \\
\hline Description & Mean & SD & Mean & SD & $\mathrm{p}$ \\
\hline Memory & 2.62 & .60 & 2.85 & .54 & 0.000 \\
\hline Cognitive & 2.81 & .70 & 2.98 & .60 & 0.000 \\
\hline Compensation & 3.10 & .55 & 3.18 & .42 & 0.002 \\
\hline Metacognitive & 2.66 & .62 & 2.83 & .51 & 0.000 \\
\hline Affective & 2.39 & .49 & 2.47 & .42 & 0.054 \\
\hline Social & 2.87 & .69 & 3.01 & .58 & 0.000 \\
\hline
\end{tabular}

Table 5, in all the categories of strategies, girls show higher frequency of strategy use than boys. Girls means are slightly higher than boys' means at a significance level $\mathrm{p}<.05$ for five strategy groups: compensation $(\mathrm{p}<.002)$, memory, metacognitive, cognitive and social strategies ( $p<.000)$. However, in the use of affective strategies the difference is not of statistical significance $(p<.54)$.

\subsection{Relationship between strategy use, gender and proficiency level}

Table 6, unlike table 4 and 5, allows within and between groups comparisons through the running of mean scores of the SILL by both gender and proficiency level. This procedure shows a rather clear and precise picture of this research's population and its distribution according to the SILL categories. That is to say, in table 6, we know whose boys or whose girls use learning strategies more than the others: first year or fourth year. 
Table 6. Mean Scores of the SILL Categories by Gender and Proficiency Level

\begin{tabular}{cllllllllll}
\hline & \multicolumn{2}{c}{$\begin{array}{c}\text { Boys } \\
(\mathbf{n = 4 0})\end{array}$} & \multicolumn{3}{c}{$\begin{array}{c}\text { Girls } \\
(\mathbf{n = 3 4 )}\end{array}$} & \multicolumn{3}{c}{$\begin{array}{c}\text { Boys } \\
(\mathbf{n = 2 0})\end{array}$} & \multicolumn{3}{c}{$\begin{array}{c}\text { Girls } \\
(\mathbf{n = 3 0})\end{array}$} \\
\hline Description & Mean & SD & Mean & SD & p & Mean & SD & Mean & SD & p \\
Memory & 2.52 & .68 & 2.87 & .55 & .002 & 2.85 & .51 & .54 & .52 & 0.000 \\
Cognitive & 2.84 & .77 & 3.00 & .59 & .000 & 2.98 & .62 & .60 & .61 & 0.000 \\
Compensation & 3.05 & .53 & 3.10 & .38 & .002 & 3.18 & .57 & .42 & .46 & 0.016 \\
Metacognitive & 2.66 & .69 & 2.89 & .52 & .000 & 2.83 & .54 & .51 & .50 & 0.000 \\
Affective & 2.37 & .57 & 2.50 & .47 & .146 & 2.47 & .40 & .42 & .37 & 0.171 \\
Social & 2.84 & .74 & 3.07 & .59 & .004 & 3.01 & .63 & .58 & .57 & 0.000 \\
\hline
\end{tabular}

According to table 6, in both university levels, the mean scores of girls are higher than the scores of boys in five of the SILL categories at a significance level $\mathrm{p}<.05$, although in the affective category the difference is not significant ( $\mathrm{p}<.146$ for first year students, $\mathrm{p}<.171$ for fourth year students). In short, girls use all six categories more often than boys, and the three most preferred strategies for boys and girls in both university years are compensation, social and cognitive strategies.

Table 6 also shows that the reported strategy use by girls varies according to university year. Although perhaps not at a level of significance, first year girls show higher use than fourth year of all strategy categories, with the exception of compensation strategies. On the contrary, first year boys report a higher use of strategy than fourth year boys only in the cognitive strategy category.

\section{Conclusion}

This study is an attempt at exploring vocabulary learning strategies used by a group of Moroccan EFL students at Mohammed V University, and the possible effects of proficiency -as reflected by study level- and gender on strategy use. Several important findings are made some of which turned out to be congruent with the major trends in L2 vocabulary research. The students consciously employ a variety of vocabulary learning strategies with moderate frequency. They choose compensation strategies as the most frequently used ones, whereas, they possibly avoid, or are unaware of how to apply, affective strategies. This pattern probably reflects the efforts of learners to overcome the limitations or gaps they feel in speaking and writing through using both linguistic and non-linguistic cues. Furthermore, the findings of this study support the assumption that there is a relationship between gender difference and the choice of strategies. A significant difference is found between female and male students in the use of strategies in this study. Another conclusion based on the major findings is that the use of strategies varies with study level. Fourth year students use compensation, and memory strategies more often than first year students, whereas, first year students use metacognitive, cognitive, and social strategies significantly more often than fourth year students.

A number of pedagogical implications can be derived from this research. First, learners of English as a foreign language should learn to recognize the learning styles and strategies they use and be advised to select the most appropriate techniques for the instructional environment through strategy instruction. Second, teachers should become more aware of the strategies their student (do not) use so as to develop a strategy instruction program compatible with their students' ways of learning. Third, teachers can help students identify their current learning strategies by means of a variety of data collection methods; surveys, one-on-one and group interviews, diaries, think-aloud protocols or other means. Fourth, language curricula, materials and instructional approaches should incorporate diversified activities to accommodate the various characteristics of the learners found in the foreign language classroom. In addition, use of appropriate learning strategies can enable students to take responsibility for their own learner autonomy, independence and self-direction (Dickinson, 1987). Finally, this study suggests that students should be exposed to many strategies. During the data collection process, some students said that they didn't know that there are so many different strategies to learn vocabulary.

In conclusion, it is evident that gender and proficiency are related to which strategies students choose and the frequency with which they use them. More research is needed in this relatively new area of vocabulary acquisition to establish how effective strategy use may be facilitated by both language teachers and language students.

\section{References}

[1] R.L. Oxford, Language learning strategies: what every teacher should know (Boston, Newbury House, 1990).

[2] J.C. Richards, The role of vocabulary teaching, TESOL Quarterly, 10(1), 1976, 77-89.

[3] M. H. Long and J.C Richards, Second language vocabulary acquisition (Cambridge, Cambridge University Press, 1997).

[4] P. Meara, The study of lexis in interlanguage, A. Davies, A. Howart, and C. Criper (Ed.), Interlanguage, (Edinburgh, Edinburgh University Press, 1984) 225-235.

[5] E. Levenston, Second language acquisition: issues and problems, Interlanguage studies bulletin, 4(2), 1979, 147-160

[6] S. Gass, Second language vocabulary acquisition, Annual Review of Applied Linguistics, 9, 1988, 92-106.

[7] E. Hatch, Psycholinguistics: a second language perspective (Rowley, MA: Newbury House, 1983).

[8] S. Gass and L. Selinker, Second language acquisition: an introductory course (Mahwah, NJ: Lawrence Erlbaum Associates, 2001). 
[9] C.B. Zimmerman, Historical trends in second language vocabulary instruction, in J. Coady and T. Huckin (Ed.), Second language vocabulary acquisition, (Cambridge: Cambridge University Press, 1997) 5-19.

[10] W. Levelt, Speaking: from intention to articulation (Cambridge: the MIT press, 1989).

[11] D. Singleton, Exploring the second language mental lexicon (Cambridge: Cambridge University Press, 1999).

[12] B. Henriksen, Remembering foreign language vocabulary: acoustic and semantic parameters, Studies in Second Language Acquisition, (21), 1999, 303-317.

[13] S.D. Krashen, We acquire vocabulary and spelling by reading: additional evidence for the input hypothesis, The Modern Language Journal, (73), 1989, 440-464.

[14] N. Ellis, Vocabulary acquisition: psychological perspectives, The Language Teacher, 18 (2), 1995, 12-16.

[15] N. Schmitt and M. McCarthy, Vocabulary: description, acquisition and pedagogy (Cambridge, Cambridge University Press, 1997).

[16] Y. Gu and R.K. Johnson, Vocabulary learning strategies and language learning outcomes, Language Learning, 46(4), 1996, 643679.

[17] A. Mochizuki, Language learning strategies used by Japanese university students, RELC Journal, 30 (2), $1999,101-113$.

[18] J.M. Green and R.L. Oxford, A closer look at learning strategies, L2 proficiency, and gender, TESOL Quarterly, $29,1995,261-267$.

[19] I. Stoffer, University foreign language students' choice of vocabulary learning strategies as related to individual difference variables, doctoral diss., University of Alabama, USA, 1995.

[20] N. Schmitt, Vocabulary learning strategies, N. Schmitt and M. McCarthy (Ed.), Description, Acquisition and Pedagogy, (MA: Cambridge University Press, 1997) 199-227.

[21] R.L. Oxford and J. Burry-Stock, Assessing the use of language learning strategies worldwide with the ESL/EFL version of the strategy inventory of language learning (SILL), System 23 (1), 1995, 1-23.

[22] R.L. Oxford, Research on language learning strategies: methods, findings and instructional issues, The Modern Language Journal, 73, 1989, 403-419.

[23] P. D. McIntyre, Toward a social psychological model of strategy use, Foreign language journals 27 (2), 1994, $185-195$.

[24] R. L. Politzer, An exploratory study of self-reported language learning behaviours and their relation to achievement. Studies in Second Language Acquisition, 6, 1983, 54-65.

[26] H. W. Lee, Investigating the factors affecting the use of foreign language learning and comparing the strategy use of EFL and ESL students, English Teaching, 48, 1994, 51-66.

[27] Y. M. Kim, The effect of gender and learning context on the use of language learning strategies, English Teaching, 50, 1995, 331345 .

[28] M. Ehrman and R. L. Oxford, Vive la difference? Reflections on sex differences in use of language learning strategies, Foreign Language Annals, 21, 1988, 321-329.

[29] A.U. Chamot, The learning strategies of ESl students, A. Wenden and J. Rubin (Ed.), Learner Strategies in Language Learning, (New York: Prentice Hall, 1987) 171-187.

[30] A.D. Cohen and E. Aphek, Retention of second language vocabulary over time: investigating the role of mnemonic associations, System, 8, 1980, 221-235. 